\title{
Tolperisone for the Treatment of Acute Muscle Spasm of the Back: Results from the Dose-Ranging Phase 2 STAR Study (NCT03802565)
}

This article was published in the following Dove Press journal: Journal of Pain Research

\author{
Srinivas Nalamachu' \\ Joseph Pergolizzi (iD) ${ }^{2}$ \\ Randall Kaye ${ }^{3}$ \\ 'Mid America PolyClinic, Overland Park, \\ KS, USA; ${ }^{2}$ NEMA Research, Naples, FL, \\ USA; ${ }^{3}$ Neurana Pharmaceuticals, Inc., San \\ Diego, CA, USA
}

Objective: Use of skeletal muscle relaxants (SMRs) for acute muscle spasm is confounded by central nervous system adverse events (AEs), including somnolence. Tolperisone is an SMR that does not appear to be associated with somnolence. The aim of this study was to assess the safety and efficacy of tolperisone versus placebo in subjects with acute muscle spasm of the back.

Methods: STAR (NCT03802565) was a double-blind, randomized, placebo-controlled phase 2 study in subjects with back pain due to acute muscle spasm. Subjects were randomized 1:1:1:1:1 to tolperisone $50,100,150$, or $200 \mathrm{mg}$ three times daily (TID) or placebo for 14 days. The primary efficacy endpoint was subject-rated pain "right now" using a numeric rating scale on day 14 .

Results: Subjects (tolperisone, $n=337$; placebo, $n=78$ ) were enrolled at 38 US clinical sites. Tolperisone was well tolerated, with AEs in $18.1 \%$ of subjects receiving tolperisone versus $14.1 \%$ of subjects receiving placebo. Headache $(7.1 \%)$ and diarrhea $(2.4 \%)$ were the most frequent AEs in tolperisone-treated subjects versus $3.8 \%$ and $0 \%$, respectively, in placebo-treated subjects. Somnolence was reported in $1.2 \%$ and $2.6 \%$ of subjects treated with tolperisone and placebo, respectively. Mean change from baseline in numeric rating scale score of pain "right now" on day 14 was -3.5 for placebo versus $-4.2,-4.0,-3.7$, and -4.4 for tolperisone $50,100,150$, and $200 \mathrm{mg}$ TID, respectively (linear test of trend on the least-squares mean difference [treatmentplacebo]; $\mathrm{p}=0.0539$ ). In an analysis of pairwise estimates (treatment-placebo), the greatest numerical difference and significance were observed for tolperisone $200 \mathrm{mg}$ TID ( $p=0.0040)$. Several secondary endpoints trended toward significance for tolperisone $200 \mathrm{mg}$ TID versus placebo.

Conclusion: Tolperisone $200 \mathrm{mg}$ TID may be a promising treatment for acute muscle spasm, without the somnolence associated with SMRs. The safety and efficacy of tolperisone should be evaluated in a phase 3 trial.

Keywords: skeletal muscle relaxant, tolperisone, acute muscle spasm, somnolence

\section{Plain Language Summary}

Acute muscle spasm of the back, the leading cause of disability worldwide, is a common reason for seeking medical care. The use of skeletal muscle relaxants (SMRs) for acute muscle spasm is common but is confounded by central nervous system adverse events, such as somnolence. Tolperisone, an SMR being developed in the United States, does not appear to be associated with somnolence. In the STAR (ClinicalTrials.gov number NCT03802565), double-blind, randomized, placebo-controlled phase 2 study, the safety and efficacy of
Correspondence: Randall Kaye Neurana Pharmaceuticals, Inc., 4370 La Jolla Village Drive, Suite 860, San Diego, CA 92122, USA

Tel +I 858-732-0708

Email rkaye@neuranapharma.com 
tolperisone compared with placebo was evaluated in subjects with acute muscle spasm of the back. Subjects (tolperisone, $\mathrm{n}=337$; placebo, $\mathrm{n}=78$ ) were enrolled at 38 US clinical sites. Tolperisone was well tolerated, with adverse events in $18.1 \%$ of subjects receiving tolperisone compared with $14.1 \%$ of subjects receiving placebo. Importantly, the rate of somnolence was comparable between tolperisone-treated subjects (1.2\%) and subjects receiving placebo $(2.6 \%)$. Linear test of trend on the leastsquares mean difference (treatment-placebo) for the mean change from baseline in day 14 numeric rating scale score of pain "right now" (the primary efficacy endpoint) approached statistical significance $(\mathrm{p}=0.0539)$. In an analysis of pairwise estimates (treatment-placebo), the greatest numerical difference and significance were observed for tolperisone $200 \mathrm{mg}$ TID ( $p=0.0040)$. Several secondary endpoints trended toward significance for the tolperisone $200 \mathrm{mg}$ group versus placebo. Given the lack of somnolence and the effective relief of pain, tolperisone $200 \mathrm{mg}$ TID may be promising for the treatment and management of acute muscle spasm.

\section{Introduction}

Acute muscle spasm is associated with a wide range of conditions, including back pain. ${ }^{1}$ Back pain is common and has a global lifetime prevalence of approximately $38.9 \%$; it is a frequent reason for seeking medical care and represents a leading cause of disability. ${ }^{1-4}$

Treatment approaches for acute muscle spasm include physical therapy, nonsteroidal anti-inflammatory drugs, acetaminophen, or skeletal muscle relaxants (SMRs). ${ }^{5}$ SMRs have been commonly prescribed for decades, and while they do provide meaningful short-term pain relief, their use is confounded by high rates of central nervous system (CNS) adverse events (AEs), primarily somnolence. Consequently, SMRs carry warnings about the risk of driving and operating heavy machinery while using them. ${ }^{1,6}$ Opioids are also used but are associated with addiction and public health issues. $1,7,8$

Tolperisone, a centrally acting, nonopioid, oral SMR, has been available in Europe and Asia for decades; at doses up to $900 \mathrm{mg} / \mathrm{day}$, it has been used to treat acute and painful muscle spasm and spasticity in adults and elderly individuals. In contrast with other centrally acting SMRs, tolperisone use does not appear to be associated with somnolence or cognitive impairment. ${ }^{9-15}$

An ultra-pure formulation of tolperisone has been developed for use in the United States using a synthetic pathway that has reduced the impurity and degradant levels below International Council for Harmonisation guidelines. Based on prior clinical studies in the United
States and clinical experience in Europe and Asia, doses of tolperisone 50, 100, 150, and $200 \mathrm{mg}$ three times daily (TID) were selected to be evaluated versus placebo for the treatment of acute muscle spasm in this phase 2 doseranging study.

\section{Methods}

\section{Study Design and Participants}

STAR (ClinicalTrials.gov, NCT03802565) was a doubleblind, randomized, placebo-controlled, parallel-group, phase 2 dose-ranging study of the safety and efficacy of tolperisone or placebo administered TID in subjects experiencing acute muscle spasm of the back. Subjects received study drug TID for 14 days and completed daily dosing diaries and electronic patient-reported outcome assessments. Potential clinical sites were selected based on their experience in clinical research and pain, with subjects recruited through self-referral or physician referrals. Subjects attended clinic assessments on study days 4 and 14 and on a follow-up visit on day 28. The study was approved by the institutional review board at each site and was conducted in accordance with the Declaration of Helsinki. All subjects provided written informed consent.

Ambulatory subjects aged 18 to 65 years with current back pain and/or stiffness due to acute muscle spasm starting within 7 days prior to study entry and more than 8 weeks after the last episode of back pain who could provide written informed consent were included in the study. Pain was required to be localized below the neck and above the inferior gluteal folds with an intensity of $\geq 4$ on the subject-rated "right now" pain-intensity numeric rating scale $(\mathrm{NRS} ; 0=$ no pain to $10=$ worst possible pain). Subjects were required to discontinue all medications used for the treatment of pain or muscle spasm on day 1 of the study. Subjects were also to refrain from vigorous physical activity, heat and ice packs, and nonpharmacological therapies (ie, acupuncture, chiropractic adjustment, massage, transcutaneous electrical nerve stimulation, and physiotherapy) from days 1 to 14 . Subjects were ineligible if they had experienced chronic pain for the previous 3 months or longer, radicular pain in the lower extremity, sciatica pain down the leg, pain below the knee (indicative of lumbar radiculopathy), radicular pain in the upper extremity radiating into the forearm or hand (indicative of cervical radiculopathy), or concomitant severe pain in a region other than the back. Subjects were also ineligible if they had undergone a spinal surgery 
within 1 year of study entry or had back pain due to a major trauma unless resolved for more than 1 year.

\section{Study Drug Administration}

Eligible subjects were randomly assigned 1:1:1:1:1 to tolperisone $50,100,150$, or $200 \mathrm{mg}$ TID or to placebo for 14 days. Use of acetaminophen (ie, a single dose of $500 \mathrm{mg}$ up to TID) was permitted as rescue medication for subjects experiencing significant pain post randomization; rescue medication was not permitted on study days 4 and 14 Subjects were required to record their daily dosing information and use of rescue medication on the trial app on their smartphones, and site staff reviewed this information with the subject at each visit to assess compliance. Subjects were instructed to record their pain assessment prior to using rescue medication.

\section{Study Assessments Safety Assessments}

Safety endpoints included the incidence of AEs and serious AEs; clinical evaluations, including vital signs, orthostatic effects of blood pressure, physical examinations, and 12-lead electrocardiogram; laboratory tests (ie, blood chemistry, hematology, and urinalysis); and a visual analog scale (VAS) for subject-reported sleepiness measured at day 4 with a tablet ePRO (electronic patient-reported outcomes; 0-10 scale on which $0=$ "wide awake" and 10 = "very sleepy; difficulty remaining awake").

\section{Efficacy Assessments}

The primary efficacy endpoint was subject-rated pain "right now" due to acute muscle spasm of the back using a 10point $\operatorname{NRS}(0=$ no pain and $10=$ worst possible pain $)$ on day 14. Secondary efficacy endpoints were assessments administered on a study site-provided tablet or captured by the subject with smartphone/trial application and included subject-rated pain "right now" using NRS on day 4, subjectrated average pain over the past $1 \mathrm{hr}$ and $12 \mathrm{hrs}$ using NRS on days 1 to 14 (measured in the morning and evening), subject-rated average pain at rest and with movement using NRS on days 1 to 14 (measured in the evening), subject rating of medication helpfulness (SRMH) on days 4 and 14 using a 1 to 5 scale $(1=$ poor, $2=$ fair, $3=\operatorname{good}, 4=$ very good, 5 = excellent), time to relief of pain (days) from baseline using subject-rated NRS over the past $12 \mathrm{hrs}$ (relief $=$ first NRS score of $\leq 2$ ), Clinician's Global Impression of Severity and Patient's Global Impression of Severity using a 1 to 5 scale $(1=$ poor, $2=$ fair, $3=$ good, $4=$ very good, $5=$ excellent) at baseline (day 1), Clinician's Global Impression of Change and Patient's Global Impression of Change (PGIC) using a 1 to 7 scale $(1=$ very much worse, $2=$ much worse, $3=$ minimally worse, $4=$ no change, $5=$ minimally improved, $6=$ much improved, $7=$ very much improved) on days 4 and 14, fingers to floor distance at baseline (day 1) and days 4 and 14, Oswestry Pain and Disability Index (ODI) assessment at baseline (day 1) and days 4 and 14, daily use of rescue medication, and subject-rated quality of sleep on a 1 to 5 scale $(1=$ no sleep at all to $5=$ slept all night) from days 1 to 14 .

\section{Statistical Analysis}

Safety analyses were conducted on the safety population, which included all subjects who received $\geq 1$ dose of study drug. AEs were mapped to preferred terms and system organ classes using the Medical Dictionary for Regulatory Activities, version 21.1. Treatment groups describing the day 4 VAS ratings of sleepiness were compared to placebo using an analysis of variance model with observed values as the response and main effects for the treatment group. Efficacy endpoints were analyzed using the intent-totreat population, which included all randomized subjects who received $\geq 1$ dose of study medication. Analysis of NRS subject-rated pain "right now" on day 14 was performed using a linear test of trend across all tolperisone doses using a mixed-effect model for repeated measures with an unstructured covariance matrix and including factors for treatment group and visit as fixed effects, the treatment by visit interaction, and the baseline NRS rating as a covariate. The primary analysis was based on all available data without imputation. The observed NRS rating and change from baseline values are presented using descriptive statistics for each treatment group, with a p-value for the overall trend on day 14. The least-squares mean (LSM) estimates and least-squares mean differences (LSMDs) for each tolperisone dose level versus placebo are presented with 95\% confidence intervals (CIs) of the LSMD and associated p-values for the observed values at the day 14 visit.

\section{Results}

\section{Subject Disposition}

Four-hundred fifteen subjects at 38 US clinical sites (listed in the Supplemental Material) were randomized to receive tolperisone (50 mg TID, $\mathrm{n}=82 ; 100 \mathrm{mg}$ TID, $\mathrm{n}=87 ; 150 \mathrm{mg}$ TID, $\mathrm{n}=83 ; 200 \mathrm{mg}$ TID, $\mathrm{n}=85)$ or placebo $(\mathrm{n}=78)$ (Figure 1). Most 


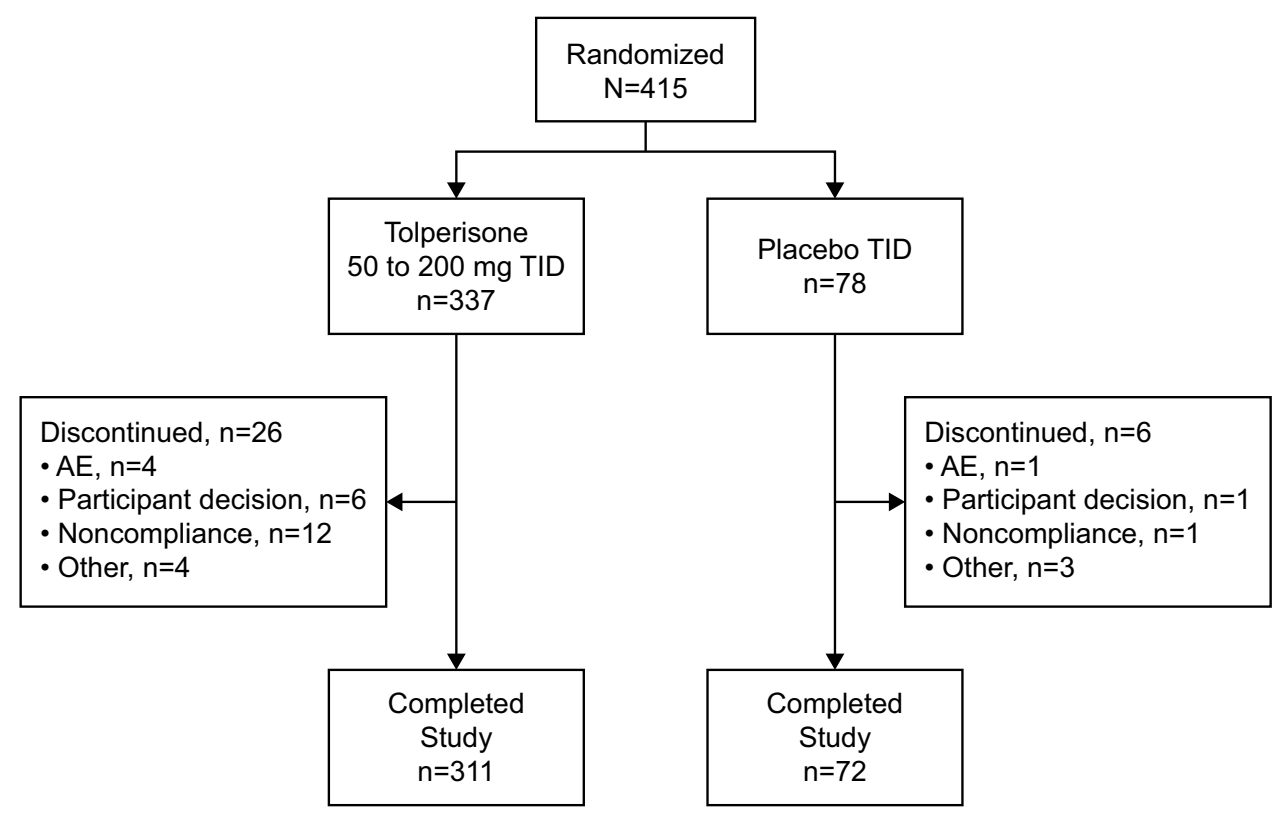

Figure I Subject disposition. AE, adverse event; TID, three times daily.

subjects $(92.3 \%$ in both the total tolperisone and placebo groups) completed the study. Among subjects receiving tolperisone, the most common reasons for early discontinuation were noncompliance $(\mathrm{n}=12)$ and subject request $(\mathrm{n}=6)$. Of note, only four subjects $(1.2 \%)$ receiving tolperisone discontinued due to AEs, with no subjects discontinuing due to lack of effect.

\section{Baseline Demographics and Characteristics}

Subject demographics and characteristics were well balanced across all treatment groups (Table 1). In the total tolperisone and placebo groups, respectively, 54.6\% (184/337) and 62.8\% (49/78) were female, 57.9\% (195/ $337)$ and $56.4 \%(44 / 78)$ were white, and mean age was 43.6 and 41.6 years.

\section{Safety}

AEs were reported by $12.2 \%$ (10/82), $18.4 \%$ (16/87), $18.1 \%$ $(15 / 83)$, and $23.5 \%(20 / 85)$ of subjects in the tolperisone $50 \mathrm{mg}$ TID, $100 \mathrm{mg}$ TID, $150 \mathrm{mg}$ TID, and $200 \mathrm{mg}$ TID dose groups, respectively, and in $14.1 \%(11 / 13)$ of those receiving placebo (Table 2). The most common AEs reported by subjects receiving tolperisone were headache $(7.1 \%, 24 / 337)$ and diarrhea $(2.4 \%, 8 / 337)$. Across the tolperisone $50 \mathrm{mg}$ TID, $100 \mathrm{mg}$ TID, $150 \mathrm{mg}$ TID, and $200 \mathrm{mg}$ TID dose groups, respectively, headache was reported by $3.7 \%(3 / 82), 5.7 \%(5 / 87), 9.6 \%(8 / 83)$, and $9.4 \%(8 / 85)$ of subjects, and diarrhea was reported by $2.4 \%$ (2/82), $2.3 \%$ (2/ $87), 3.6 \%(3 / 83)$, and $1.2 \%(1 / 85)$ of subjects. Headache generally resolved over the first 24 to 48 hrs of dosing.

Somnolence and hypersensitivity are AEs typically associated with SMRs and can often limit clinical use. Somnolence was reported by $0 \%, 3.4 \%(3 / 87), 0 \%$, and $1.2 \%(1 / 85)$ of subjects in the tolperisone $50 \mathrm{mg}$ TID, $100 \mathrm{mg}$ TID, $150 \mathrm{mg}$ TID, and $200 \mathrm{mg}$ TID dose groups, respectively, versus $2.6 \%$ $(2 / 78)$ of those in the placebo group (Table 3$)$. All somnolence events were assessed as mild or moderate, and none led to subject discontinuation. Four subjects receiving tolperisone reported hypersensitivity events (Table 3), including allergic dermatitis (100 mg TID dose group), urticaria (150 mg TID dose group), and pruritus and maculopapular rash (200 mg TID dose group). All hypersensitivity events were mild or moderate, with three events (urticaria, pruritus, and maculopapular rash) considered at least possibly related to tolperisone. The events of urticaria and maculopapular rash led to discontinuation of study drug in two subjects (tolperisone $150 \mathrm{mg}$ TID and $200 \mathrm{mg}$ TID, respectively).

Treatment-related AEs were reported in 13.4\% (45/337) and $6.4 \%(5 / 78)$ of participants receiving tolperisone and placebo, respectively, with headache $(6.2 \%, 21 / 337)$ and diarrhea $(2.1 \%, 7 / 337)$ the most frequent in the tolperisone groups. There were no serious AEs or deaths reported during the study. The incidence of TEAEs that led to study drug discontinuation was similar in the total tolperisone group (five subjects; $1.5 \%$ ) and in the placebo group (one subject; 
Table I Subject Demographics

\begin{tabular}{|c|c|c|c|c|c|c|}
\hline & \multirow[t]{2}{*}{ Placebo $(n=78)$} & \multicolumn{5}{|l|}{ Tolperisone } \\
\hline & & $\begin{array}{l}50 \mathrm{mg} \text { TID } \\
(\mathrm{n}=82)\end{array}$ & $\begin{array}{l}100 \mathrm{mg} \text { TID } \\
(\mathrm{n}=87)\end{array}$ & $\begin{array}{l}\text { I50 mg TID } \\
(n=83)\end{array}$ & $\begin{array}{l}200 \mathrm{mg} \text { TID } \\
(\mathrm{n}=85)\end{array}$ & $\begin{array}{l}\text { Total } \\
(n=337)\end{array}$ \\
\hline Mean age (SD), years & $41.6(12.37)$ & $43.5(12.58)$ & $44.4(12.20)$ & $44.3(12.09)$ & $42.0(11.96)$ & $43.6(12.19)$ \\
\hline \multicolumn{7}{|l|}{ Age category, n (\%) } \\
\hline $18-49$ years & $52(66.7)$ & 54 (65.9) & $52(59.8)$ & $50(60.2)$ & $61(71.8)$ & $217(64.4)$ \\
\hline $50-65$ years & $26(33.3)$ & $28(34.1)$ & $35(40.2)$ & $33(39.8)$ & $24(28.2)$ & $120(35.6)$ \\
\hline \multicolumn{7}{|l|}{ Sex, n (\%) } \\
\hline Male & $29(37.2)$ & $37(45.1)$ & $30(34.5)$ & $42(50.6)$ & $44(51.8)$ & I53 (45.4) \\
\hline Female & $49(62.8)$ & $45(54.9)$ & $57(65.5)$ & $4 \mid(49.4)$ & $4 \mid(48.2)$ & $184(54.6)$ \\
\hline \multicolumn{7}{|l|}{ Ethnicity, n (\%) } \\
\hline Hispanic or Latino & $16(20.5)$ & $13(15.9)$ & $18(20.7)$ & $22(26.5)$ & $20(23.5)$ & $73(21.7)$ \\
\hline Not Hispanic or Latino & $62(79.5)$ & $69(84.1)$ & $69(79.3)$ & $61(73.5)$ & $65(76.5)$ & $264(78.3)$ \\
\hline \multicolumn{7}{|l|}{ Race, ${ }^{a}$ n (\%) } \\
\hline American Indian/Alaska Native & $3(3.8)$ & $\mathrm{I}(\mathrm{I} .2)$ & 0 & I (I.2) & 0 & $2(0.6)$ \\
\hline Asian & $4(5.1)$ & $\mathrm{I}(\mathrm{I} .2)$ & $4(4.6)$ & $2(2.4)$ & $4(4.7)$ & II (3.3) \\
\hline Black or African American & $30(38.5)$ & $29(35.4)$ & $32(36.8)$ & $30(36.1)$ & $35(4 \mid .2)$ & $126(37.4)$ \\
\hline Native Hawaiian/Pacific Islander & 0 & I (I.2) & I (I.I) & I (1.2) & 0 & $3(0.9)$ \\
\hline White & $44(56.4)$ & $50(6 \mid .0)$ & $50(57.5)$ & $50(60.2)$ & $45(52.9)$ & 195 (57.9) \\
\hline Other & 0 & 0 & 0 & 0 & $\mathrm{I}(\mathrm{I} .2)$ & I (0.3) \\
\hline \multicolumn{7}{|l|}{ Body mass index $\left(\mathrm{kg} / \mathrm{m}^{2}\right)$} \\
\hline Mean (SD) & $28.53(4.33)$ & $28.23(4.27)$ & $28.48(4.10)$ & $28.34(3.99)$ & $28.45(4.35)$ & $28.38(4.16)$ \\
\hline Range & $19.5-35.0$ & $19.4-35.0$ & $20.9-35.0$ & $19.8-35.0$ & $20.0-35.0$ & $19.4-35.0$ \\
\hline
\end{tabular}

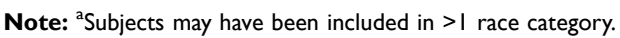

Abbreviation: SD, standard deviation.

1.3\%). These included headache in the tolperisone $100 \mathrm{mg}$ TID group; nausea, vomiting, vertigo, and withdrawal syndrome (all in one subject) and urticaria (one event in one subject) in the tolperisone $150 \mathrm{mg}$ TID group; and vertigo and maculopapular rash (one subject each) in the tolperisone $200 \mathrm{mg}$ TID group. There were no significant differences between any of the tolperisone dose groups and placebo in subject-reported sleepiness as measured in the clinic on day 4. There were also no treatment or dose-related trends or significant findings for laboratory results, vital signs, electrocardiograms, or neurological examinations.

\section{Efficacy}

\section{Primary Efficacy Endpoint}

Subject-rated pain "right now" demonstrated a mean decrease from baseline at day 14 of $-4.2,-4.0,-3.7$, and -4.4 in the tolperisone $50 \mathrm{mg}$ TID, $100 \mathrm{mg}$ TID, $150 \mathrm{mg}$ TID, and $200 \mathrm{mg}$ TID dose groups, respectively, versus -3.5 in the placebo group (Figure 2). The overall trend in NRS rating of pain "right now" across dose groups at day 14 trended toward statistical significance $(\mathrm{p}=0.0539)$. LSMDs (treatment-placebo) from the mixedeffect model for repeated measures estimates of NRS at day 14 were $-0.6(\mathrm{p}=0.0240),-0.5(\mathrm{p}=0.0506),-0.2$ $(\mathrm{p}=0.4443)$, and $-0.8 \quad(\mathrm{p}=0.0040)$ in the tolperisone $50 \mathrm{mg}$ TID, $100 \mathrm{mg}$ TID, $150 \mathrm{mg}$ TID, and $200 \mathrm{mg}$ TID dose groups, respectively (Figure 3 ).

\section{Secondary Efficacy Endpoints}

Although the secondary endpoints were not powered to demonstrate statistical significance (Table 4), several indicated numerical improvement with tolperisone versus placebo. The proportion of subjects who experienced pain relief (NRS $\leq 2)$ from baseline over the past $12 \mathrm{hrs}$ starting at day 2 was $58.0 \%$ (47/81), 63.1\% (53/84), 46.9\% (38/81), and $52.9 \%(45 / 85)$ in the tolperisone $50 \mathrm{mg}$ TID, $100 \mathrm{mg}$ TID, $150 \mathrm{mg}$ TID, and $200 \mathrm{mg}$ TID dose groups, respectively, compared to $46.2 \%$ (36/78) in the placebo group. All tolperisone groups had a hazard ratio $>1$, indicating a numerically faster treatment effect. Moreover, although there were no differences between tolperisone groups and placebo in 
Table 2 Summary of Adverse Events

\begin{tabular}{|c|c|c|c|c|c|c|}
\hline & \multirow[t]{2}{*}{ Placebo $(n=78)$} & \multicolumn{5}{|l|}{ Tolperisone } \\
\hline & & $\begin{array}{l}50 \mathrm{mg} \text { TID } \\
(\mathrm{n}=82)\end{array}$ & $\begin{array}{l}100 \mathrm{mg} \text { TID } \\
(\mathrm{n}=87)\end{array}$ & $\begin{array}{l}\text { I50 mg TID } \\
(n=83)\end{array}$ & $\begin{array}{l}200 \mathrm{mg} \text { TID } \\
(\mathrm{n}=85)\end{array}$ & $\begin{array}{l}\text { Total } \\
(n=337)\end{array}$ \\
\hline Total number of $A E s, n$ & 13 & 13 & 22 & 21 & 36 & 92 \\
\hline Subjects with $\geq I A E, n(\%)$ & II (14.I) & $10(12.2)$ & $16(18.4)$ & $15(18.1)$ & $20(23.5)$ & $61(18.1)$ \\
\hline Mild $^{\mathrm{a}}$ & $8(10.3)$ & $6(7.3)$ & $13(14.9)$ & $8(9.6)$ & $12(14.1)$ & $39(11.6)$ \\
\hline Moderate $^{\mathrm{a}}$ & $3(3.8)$ & $4(4.9)$ & $3(3.4)$ & $5(6.0)$ & $6(7.1)$ & $18(5.3)$ \\
\hline Severe $^{a}$ & 0 & 0 & 0 & $2(2.4)$ & $2(2.4)$ & $4(1.2)$ \\
\hline \multicolumn{7}{|l|}{ AE, n (\%) } \\
\hline Related to study drug ${ }^{\mathrm{b}}$ & $5(6.4)$ & $5(6.1)$ & $13(14.9)$ & $13(15.7)$ & $14(16.5)$ & $45(13.4)$ \\
\hline Leading to study drug discontinuation ${ }^{c}$ & $\mathrm{I}(\mathrm{I} .3)$ & 0 & $\mathrm{I}(\mathrm{I} . \mathrm{I})$ & $2(2.4)$ & $2(2.4)$ & $5(1.5)$ \\
\hline Requiring study drug dose interruption & 0 & 0 & 0 & 0 & $\mathrm{I}(\mathrm{I} .2)$ & $\mathrm{I}(0.3)$ \\
\hline Requiring study drug dose reduction & 0 & 0 & 0 & 0 & $\mathrm{I}(\mathrm{l} .2)$ & $\mathrm{I}(0.3)$ \\
\hline Death & 0 & 0 & 0 & 0 & 0 & 0 \\
\hline Serious AEs, $n$ & 0 & 0 & 0 & 0 & 0 & 0 \\
\hline
\end{tabular}

Notes: a Subjects reporting >I AE were counted only once using the highest severity. ${ }^{b}$ Subjects reporting $>$ I AE were counted only once using the closest relationship to study drug. Related events included those reported as "possibly related" or "definitely related" to study drug. "One placebo subject discontinued treatment due to an AE of blurred vision. Five tolperisone recipients discontinued treatment with a total of eight AEs (vertigo [ $\mathrm{n}=2$ ], headache, nausea, vomiting, withdrawal syndrome, urticaria, and maculopapular rash).

Abbreviations: $A E$, adverse event; TID, three times daily.

fingers to floor distance or ODI total scores, certain subcategories of the ODI did trend toward significance for the tolperisone $200 \mathrm{mg}$ TID group at day 14 . These included personal care $(\mathrm{p}=0.0519)$, walking $(\mathrm{p}=0.0949)$, and social life $(\mathrm{p}=0.0814)$. Similarly, although there were no significant differences observed at day 14 in the categories of SRMH, Clinician's Global Impression of Change, PGI-C, subjectrated quality of sleep, or subject-rated daily activity level, both SRMH and PGI-C trended toward significance for the highest tolperisone dose group (200 $\mathrm{mg}$ TID) versus placebo $(\mathrm{p}=0.0656$ and $\mathrm{p}=0.0526$, respectively) (Figures 4 and 5). The percentages of subjects taking at least one caplet of rescue medication during the treatment period were $51.2 \%$
(42/82), $41.4 \%$ (36/87), 45.8\% (38/83), and 50.6\% (43/85) in the tolperisone $50 \mathrm{mg}$ TID, $100 \mathrm{mg}$ TID, $150 \mathrm{mg}$ TID, and $200 \mathrm{mg}$ TID groups, respectively, and $52.6 \%$ (41/78) in the placebo group. Of note, $30 \%$ more subjects receiving placebo used rescue medication versus those receiving tolperisone during the first 7 days.

\section{Discussion}

When first-line options to treat acute muscle spasm have failed to deliver the desired results, patients are typically treated with an SMR (eg, cyclobenzaprine). Although SMRs can provide pain relief, ${ }^{8}$ tolerability issues, in particularly somnolence, represent a significant issue. In a meta-

Table 3 Adverse Events Typically Associated with Skeletal Muscle Relaxants

\begin{tabular}{|c|c|c|c|c|c|c|}
\hline \multirow{2}{*}{$\begin{array}{l}\text { Category, n (\%) } \\
\text { Preferred Term, n (\%) }\end{array}$} & \multirow[t]{2}{*}{ Placebo $(n=78)$} & \multicolumn{5}{|l|}{ Tolperisone } \\
\hline & & $\begin{array}{l}50 \mathrm{mg} \text { TID } \\
(\mathrm{n}=82)\end{array}$ & $\begin{array}{l}100 \mathrm{mg} \text { TID } \\
(\mathrm{n}=87)\end{array}$ & $\begin{array}{l}\text { I } 50 \mathrm{mg} \text { TID } \\
(\mathrm{n}=83)\end{array}$ & $\begin{array}{l}200 \mathrm{mg} \text { TID } \\
(\mathrm{n}=85)\end{array}$ & $\begin{array}{l}\text { Total } \\
(n=337)\end{array}$ \\
\hline Somnolence & $2(2.6)$ & 0 & $3(3.4)$ & 0 & $\mathrm{I}(\mathrm{I} .2)$ & $4(1.2)$ \\
\hline Hypersensitivity ${ }^{\mathrm{a}}$ & 0 & 0 & $\mathrm{I}(\mathrm{I} . \mathrm{I})$ & $\mathrm{I}(\mathrm{I} .2)$ & $2(2.4)$ & $4(1.2)$ \\
\hline Dermatitis allergic & 0 & 0 & $\mathrm{I}(\mathrm{I} . \mathrm{I})$ & 0 & 0 & I $(0.3)$ \\
\hline Pruritus & 0 & 0 & 0 & 0 & $\mathrm{I}(\mathrm{I} .2)$ & $\mathrm{I}(0.3)$ \\
\hline Maculopapular rash & 0 & 0 & 0 & 0 & I (I.2) & I (0.3) \\
\hline Urticaria & 0 & 0 & 0 & $\mathrm{I}(\mathrm{I} .2)$ & 0 & $\mathrm{I}(0.3)$ \\
\hline
\end{tabular}

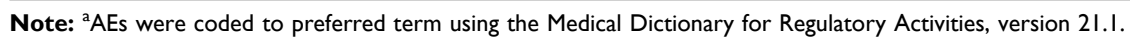




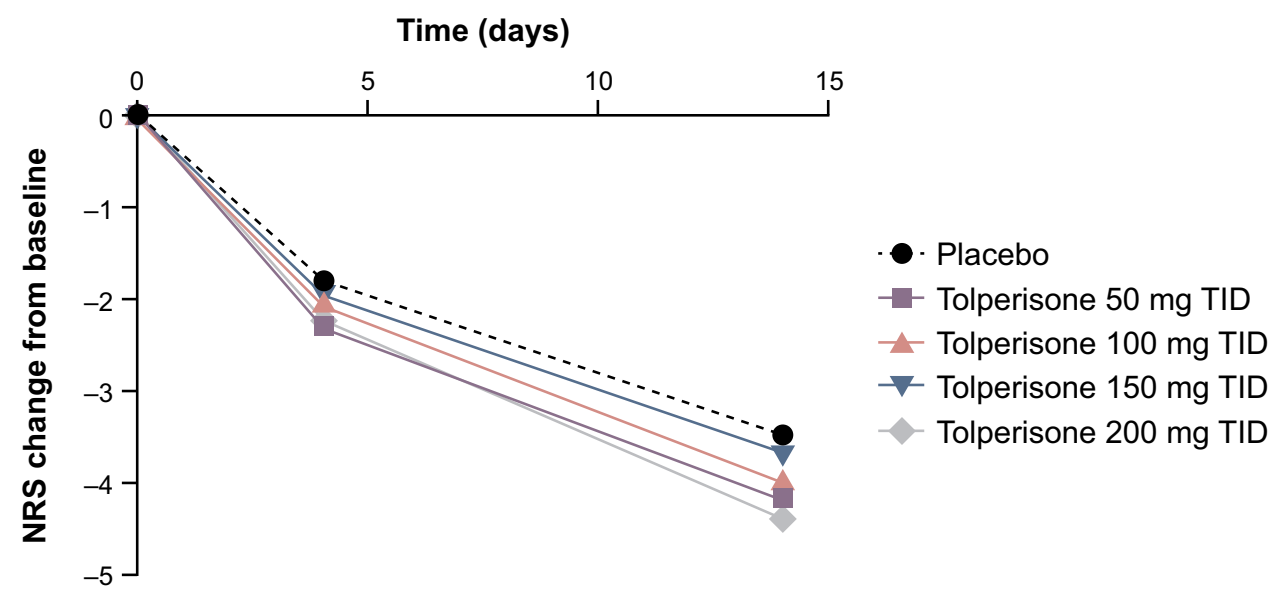

Figure 2 Change from baseline NRS "right now" scores. NRS, numerical rating scale; TID, three times daily.

analysis of 14 randomized controlled trials focused on back pain in association with muscle spasm, $20 \%$ of patients treated with cyclobenzaprine reported drowsiness. ${ }^{16}$ In two randomized placebo-controlled studies of low-dose regimens of cyclobenzaprine in acute skeletal muscle spasm, somnolence occurred in $29 \%$ and $38 \%$ of subjects receiving $5 \mathrm{mg}$ TID and $10 \mathrm{mg}$ TID, respectively. ${ }^{17}$ In a pharmacokinetic study, $100 \%$ of healthy volunteers receiving a once-daily extended-release formulation of cyclobenzaprine reported somnolence. ${ }^{18}$ In a randomized trial of acute back pain, adding cyclobenzaprine to an existing naproxen regimen did not improve functional assessments or measures of pain but did increase AEs. ${ }^{19}$ Given the widespread use of SMRs for the treatment of back pain, an effective therapeutic option must provide the pain relief that patients require without the untoward off-target CNS effects.
With decades of clinical experience, tolperisone has been shown to be effective in the treatment of acute, painful muscle spasm and spasticity; importantly, tolperisone does not appear to be associated with somnolence. $^{9-15}$ This is thought to be due to its minimal affinity for cholinergic, serotonergic, dopaminergic, and adrenergic receptors in the CNS and the resultant lack of sleepiness and impact on reaction time. ${ }^{13}$

Most tolperisone-treated patients $(92.3 \%)$ completed the study (Figure 1), and AE rates were similar in the total tolperisone and placebo groups $(18.1 \%$ and $14.1 \%$, respectively) (Table 2). This indicates an excellent tolerability profile of tolperisone. Importantly, the rates of somnolence in the tolperisone groups $(0 \%, 3.4 \%, 0 \%$, and $1.2 \%$ in the $50 \mathrm{mg}$ TID, $100 \mathrm{mg}$ TID, $150 \mathrm{mg}$ TID, and $200 \mathrm{mg}$ TID groups, respectively) were comparable

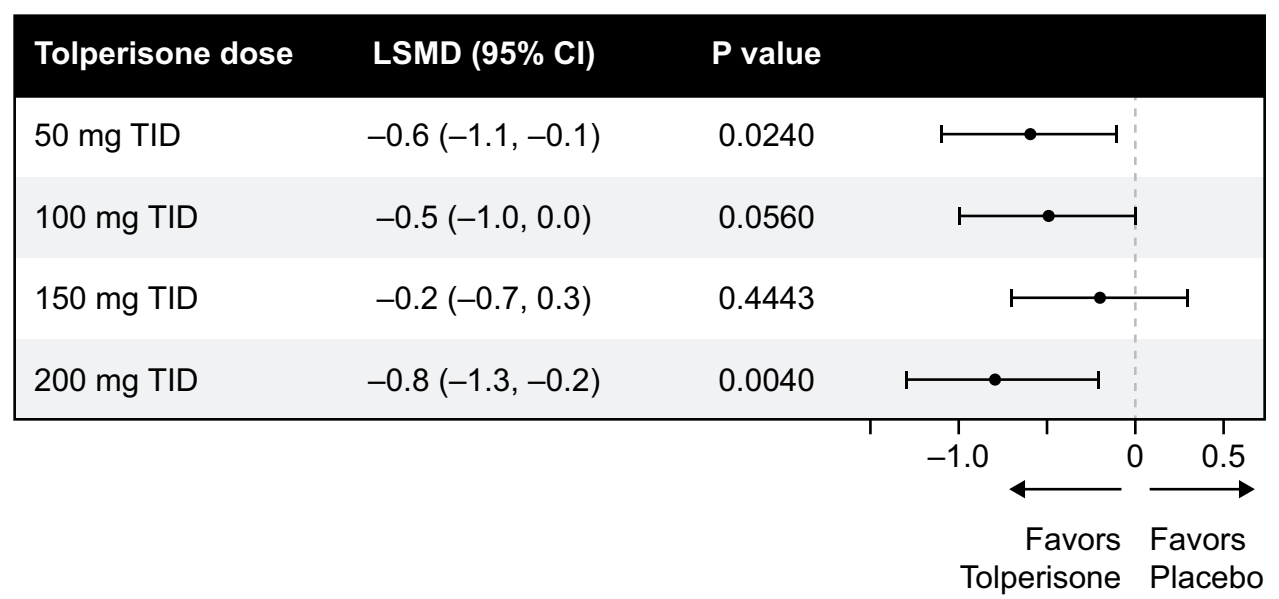

Figure 3 Numerical rating scale (NRS) "right now” least-squares mean difference (treatment-placebo) mixed-effect model for repeated measures estimate of NRS (95\% Cl). Abbreviations: $\mathrm{Cl}$, confidence interval; TID, three times daily; LSMD, least-squares mean difference. 
Table 4 Secondary Efficacy Analyses

\begin{tabular}{|c|c|c|c|c|c|}
\hline & \multirow[t]{2}{*}{ Placebo } & \multicolumn{4}{|l|}{ Tolperisone } \\
\hline & & $50 \mathrm{mg}$ TID & $100 \mathrm{mg}$ TID & 150 mg TID & $200 \mathrm{mg}$ TID \\
\hline Time to pain relief $^{a}$ & $\mathrm{n}=78$ & $n=8 I$ & $\mathrm{n}=84$ & $\mathrm{n}=8 \mathrm{I}$ & $\mathrm{n}=85$ \\
\hline Median, days (range) & $14(2,14)$ & $12(2,14)$ & $10(2,14)$ & $14(2,14)$ & $14(2,14)$ \\
\hline Hazard ratio & & 1.31 & 1.47 & 1.14 & 1.22 \\
\hline $95 \% \mathrm{Cl}$ & & $0.85,2.03$ & $0.96,2.25$ & $0.72,1.79$ & $0.79,1.89$ \\
\hline$P$ value & & 0.1975 & 0.0609 & 0.3098 & 0.2177 \\
\hline CGI-C (day I4) & $\mathrm{n}=72$ & $n=76$ & $\mathrm{n}=82$ & $n=74$ & $n=76$ \\
\hline Worse & $3(4.2)$ & 0 & $4(4.9)$ & $2(2.7)$ & $\mathrm{I}(\mathrm{I} .3)$ \\
\hline No change & $7(9.7)$ & $10(13.2)$ & II (I3.4) & $9(12.2)$ & $9(11.8)$ \\
\hline Minimally improved & $23(31.9)$ & $20(26.3)$ & $16(19.5)$ & $19(25.7)$ & $21(27.6)$ \\
\hline Much/very much improved & $39(54.2)$ & $46(60.5)$ & $51(62.2)$ & $44(59.5)$ & $45(59.2)$ \\
\hline$P$ value & & 0.2133 & 0.2982 & 0.7210 & 0.2646 \\
\hline Fingers to floor distance (day 14$)^{\mathrm{b}}$ & $\mathrm{n}=72$ & $\mathrm{n}=77$ & $n=83$ & $n=74$ & $\mathrm{n}=77$ \\
\hline LSM (SE) & $13.9(0.89)$ & I3.8 (0.86) & $13.0(0.83)$ & $14.8(0.88)$ & $12.4(0.86)$ \\
\hline LSMD (treatment minus placebo) (SE) & & $-0.1(1.24)$ & $-1.0(1.22)$ & $0.8(1.25)$ & $-1.5(1.24)$ \\
\hline $95 \% \mathrm{Cl}$ & & $-2.5,2.4$ & $-3.4,1.4$ & $-1.6,3.3$ & $-3.9,0.9$ \\
\hline$P$ value & & 0.9493 & 0.4332 & 0.5069 & 0.2250 \\
\hline ODI (day 14) ${ }^{\mathrm{b}}$ & $n=71$ & $n=77$ & $n=81$ & $n=74$ & $n=74$ \\
\hline LSM (SE) & $21.3(1.64)$ & $17.7(1.57)$ & $19.0(1.53)$ & $19.8(1.60)$ & $17.9(1.60)$ \\
\hline LSMD (Tx - placebo) (SE) & & $-3.6(2.27)$ & $-2.3(2.24)$ & $-1.6(2.29)$ & $-3.4(2.29)$ \\
\hline $95 \% \mathrm{Cl}$ & & $-8.1,0.9$ & $-6.7,2.1$ & $-6.1,2.9$ & -7.9, I.I \\
\hline$P$ value & & 0.1123 & 0.3020 & 0.4961 & 0.1376 \\
\hline Use of rescue medication & $\mathrm{n}=77$ & $n=79$ & $n=82$ & $n=79$ & $n=84$ \\
\hline Caplets/day, mean (SD) & $3.9(6.55)$ & $3.9(6.95)$ & $3.0(6.03)$ & $3.6(6.99)$ & $3.0(5.46)$ \\
\hline$P$ value ${ }^{c}$ & & 0.8942 & 0.2436 & 0.4782 & 0.5065 \\
\hline
\end{tabular}

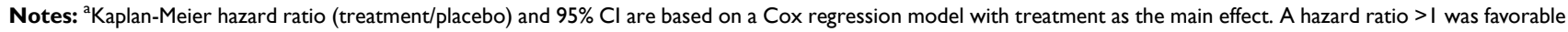
to treatment. Time to pain relief was assessed based on the NRS assessment of subject rating of pain over the past 12 hours starting at day 2 . Pain relief was defined as an NRS rating $\leq 2$ where $0=$ no pain and $10=$ worst possible pain. ${ }^{b}$ Estimates for $\mathrm{p}$-values, LSM, LSMD, and $95 \% \mathrm{Cl}$ are from an analysis of covariance model with observed total ODI score as the response, main effects for treatment group, and a covariate adjustment for baseline value. 'Wilcoxon rank-sum test pairwise comparison versus placebo. Abbreviations: CGI-C, Clinician's Global Impression of Change; CI, confidence interval; LSMD, least-squares mean difference; LSM, least-squares mean; ODI, Oswestry Disability Index; SE, standard error; TID, three times daily.

with the somnolence rate in those receiving placebo $(2.6 \%)$ (Table 3). Moreover, on the VAS for subjectreported sleepiness at day 4 , there were no significant differences in the pairwise comparisons of each tolperisone dose versus placebo ( $\mathrm{p} \geq 0.6275$ ), suggesting that tolperisone is not associated with sleepiness at any dose. Given the warning about somnolence while driving on an SMR and the FDA recommendation that all drugs with potential to impair driving should be evaluated in a dedicated driving study, ${ }^{20}$ it was important to confirm that the lack of somnolence associated with tolperisone translated into a lack of driving impairment. In a study to assess tolperisone on driving ability and cognition, measures of weaving, driving ability, cognition, and psychomotor function were similar in participants receiving tolperisone (150 mg TID) or placebo. $^{20}$ In the same study, cyclobenzaprine was found to significantly impair primary and secondary measures of driving ability. Notably, most cyclobenzaprine-treated patients did not know they were impaired, with only $3.4 \%$ of subjects reporting on day 2 that they felt unsafe. Although there is considerable clinical experience with tolperisone, there is a lack of randomized, double-blind, placebo-controlled studies $^{21}$; therefore, the lack of somnolence in this study is an important confirmatory finding.

In addition to confirming a lack of somnolence, this study was also designed to select a dose of tolperisone for the planned pivotal phase 3 study. The greatest effect in terms of relief of pain associated with acute muscle spasm of the back in this dose-ranging phase 2 study was 


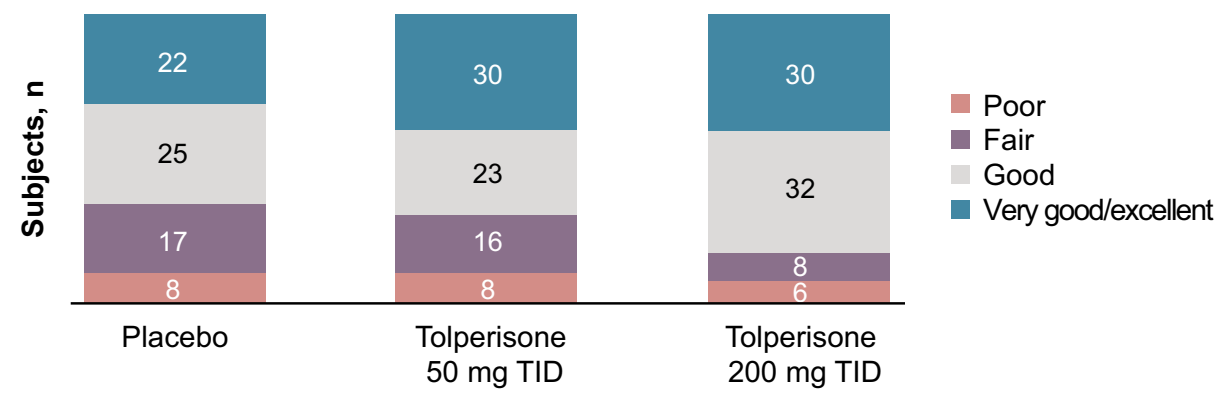

Figure 4 Rating of medication helpfulness at day 14. Abbreviation: TID, three times daily.

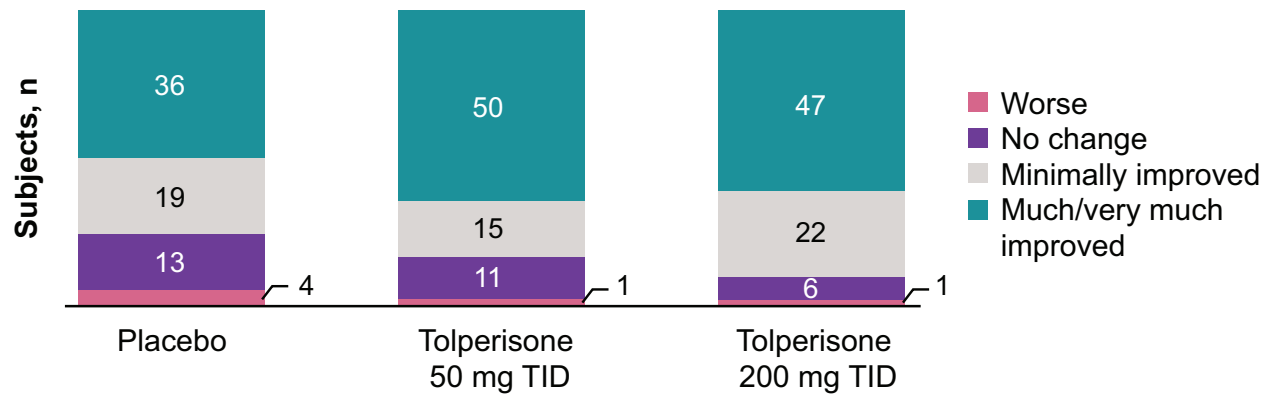

Figure 5 Patient's Global Impression of Change at day 14. Abbreviation: TID, three times daily.

generally seen at the highest dose evaluated $(200 \mathrm{mg}$ TID). The primary efficacy endpoint (ie, subject-rated pain "right now" on day 14) was significantly lower $(p=0.0040)$ at the tolperisone $200 \mathrm{mg}$ TID dose versus placebo, and the numerically lowest LSM pain scores were achieved with the highest tolperisone dose. The mean decrease in NRS subject-reported pain "right now" from baseline in the $200 \mathrm{mg}$ TID tolperisone group of -2.2 (day 4) and -4.4 (day 14) compared favorably with mean decreases in NRS patient evaluations of local pain of -3.2 (day 4) and -5.5 (day 9) with cyclobenzaprine in a doubleblind study versus placebo. ${ }^{22}$ Of note, in the cyclobenzaprine study, $31 \%$ of patients reported drowsiness. Tolperisone, like other SMRs, may take weeks to demonstrate its full impact on pain relief. Through blockade by tolperisone of voltage-gated calcium and sodium channels, ${ }^{21}$ the muscle is relaxed, thereby allowing cellular repair and a gradual relief of symptoms. This is in contrast with the mechanism of action of short-term analgesics. Consequently, the primary analysis in this study was assessed on day 14. Additional studies should evaluate earlier time points as these are clinically important.
Although the secondary endpoints were not powered to demonstrate statistical significance, a number of the secondary analyses also trended toward significance for the tolperisone $200 \mathrm{mg}$ TID dose group, including the personal care, walking, and social life subcategories of the ODI, and both the SRMH and PGI-C. It will be important to assess these findings in a phase 3 study that will be larger and appropriately powered for key secondary efficacy endpoints.

\section{Conclusions}

Tolperisone $200 \mathrm{mg}$ TID may be a promising treatment for acute muscle spasm, without the somnolence associated with SMRs. The safety and efficacy of tolperisone should be evaluated in a phase 3 trial.

\section{Abbreviations}

AE, adverse event; CGI-C, Clinician's Global Impression of Change; CI, confidence interval; CNS, central nervous system; FFD, fingers to floor; LSMD, least-squares mean difference; LSM, least-squares mean; NRS, numeric rating scale; ODI, Oswestry Disability Index; PGI-C, Patient's Global Impression of Change; PGI-S, Patient's Global Impression of Severity; SE, 
standard error; SMR, skeletal muscle relaxant; SRMH, subject rating of medication helpfulness; TID, three times daily; VAS, visual analog scale.

\section{Data Sharing Statement}

The data used and/or analyzed during this study will be available upon a reasonable request of the corresponding author by email.

\section{Ethics Approval and Informed Consent}

The study (ClinicalTrials.gov, NCT03802565) was approved by the institutional review board at each site and all subjects provided written informed consent. The clinical trial sites are listed in the Supplemental Material.

\section{Consent for Publication}

The authors gave their final approval for this version to be published and agree to be accountable for all aspects of the work.

\section{Acknowledgments}

The authors thank David Gibson, PhD, CMPP (ApotheCom), for writing and editorial assistance, which was funded by Neurana Pharmaceuticals, Inc. Data contained within this manuscript have been presented in posters at the following conferences: American Society of Interventional Pain Physicians (ASIPP) 2020, PAINWeek 2020, and 27th Napa Pain Conference (NPC) 2020.

\section{Author Contributions}

All authors contributed to the data analysis and to drafting or revising the article, agreed on the journal to which the article was submitted, gave final approval of the manuscript version to be submitted, and agreed to be accountable for all aspects of the work.

\section{Funding}

This study was funded by Neurana Pharmaceuticals, Inc.

\section{Disclosure}

S. Nalamachu is a consultant for Neurana Pharmaceuticals, Pfizer, and Lilly. J. Pergolizzi is a consultant/speaker and researcher for US WorldMeds, BDSI, Salix, Enalare, Scilex, Pfizer, Lilly, Teva, Regeneron, RedHill, Grunenthal, and Neumentum. R. Kaye is an employee of and owns stock in Neurana Pharmaceuticals. The authors report no other conflicts of interest in this work.

\section{References}

1. Patel HD, Uppin RB, Naidu AR, et al. Efficacy and safety of combination of NSAIDS and muscle relaxants in the management of acute low back pain. Pain Ther. 2019;8:121-132. doi:10.1007/s40122-019-0112-6

2. Ferguson SA, Merryweather A, These MS, et al. Prevalence of low back pain, seeking medical care, and lost time due to low back pain among manual material handling workers in the United States. $B M C$ Musculoskeletal Disord. 2019;20:243. doi:10.1186/s12891-0192594-0

3. Lim S, Vos T, Flaxman A, et al. A comparative risk assessment of burden of disease and injury attributable to 67 risk factors and risk factor clusters in 21 regions, 1990-2010: a systematic analysis for the Global Burden of Disease Study 2010. Lancet. 2012;380:2224-2260. doi:10.1016/S0140-6736(12)61766-8

4. Vos T, Flaxman AD, Naghavi M, et al. Years lived with disability (YLDs) for 1160 sequelae of 289 diseases and injuries 1990-2010: a systematic analysis for the Global Burden of Disease Study 2010. Lancet. 2012;380:2163-2196. doi:10.1016/S0140-6736(12)61729-2

5. Horsley L. ACP guidelines for the diagnosis and treatment of low back pain. Am Fam Physician. 2008;77:1607-1610.

6. Shaheed A, Maher CG, Williams KA, et al. Efficacy and tolerability of muscle relaxants for low back pain: systematic review and meta-analysis. Eur J Pain. 2017;21:228-237. doi:10.1002/ejp.907

7. Chou R, Huffman LH; American Pain Society. Medications for acute and chronic low back pain: a review of the evidence for an American Pain Society/American College of Physicians clinical practice guideline. Ann Intern Med. 2017;147:505-514. doi:10.7326/00034819-147-7-200710020-00008

8. Kiang MV, Humphreys K, Cullen MR, et al. Opioid prescribing patterns among medical providers in the United States, 2003-17: retrospective, observational study. BMJ. 2020;368:16968.

9. Pratzel HG, Alken RG, Ramm S. Efficacy and tolerance of repeated oral doses of tolperisone hydrochloride in the treatment of painful reflex muscle spasm: results of a prospective placebo-controlled double-blind trial. Pain. 1996;67:417-425. doi:10.1016/03043959(96)03187-9

10. Stamenova P, Koytchev R, Kuhn K, et al. A randomized, double-blind, placebo-controlled study of the efficacy and safety of tolperisone in spasticity following cerebral stroke. Eur J Neurol. 2005;12:453-461. doi:10.1111/j.1468-1331.2005.01006.x

11. Agarwal S, Patel T, Shah N, et al. Comparative study of therapeutic response to baclofen vs tolperisone in spasticity. Biomed Pharmacother. 2017;87:628-635. doi:10.1016/j.biopha.2017.01.005

12. European Medicines Agency. Assessment report for tolperisone-containing medicinal products. Procedure number: EMEA/H/A-31/1311; 2013. Available from: https://www.ema. europa.eu/en/documents/referral/assessment-report-tolperisonecontaining-medicinal-products_en.pdf. Accessed January 21, 2020.

13. Dulin J, Kovacs L, Ramm S, et al. Evaluation of sedative effects of single and repeated doses of $50 \mathrm{mg}$ and $150 \mathrm{mg}$ tolperisone hydrochloride. Results of a prospective, randomized, double-blind, placebo-controlled trial. Pharmacopsychiatry. 1998;31:137-142.

14. Rao R, Panghate A, Chandanwale A, et al. Clinical comparative study: efficacy and tolerability of tolperisone and thiocolchicoside in acute low back pain and spinal muscle spasticity. Asian Spine J. 2012;6:115-122. doi:10.4184/asj.2012.6.2.115

15. Prabhoo R, Keny S, Prabhoo T, et al. A Phase IV observational multi-centre, open-label study on efficacy and safety of tolperisone $150 \mathrm{mg}$ in patients with painful muscle spasm associated with degenerative or inflammatory diseases of the musculoskeletal system. J Assoc Physicians India. 2011;59:33-37. 
16. Browning R, Jackson JL, O’Malley PG. Cyclobenzaprine and back pain: a meta-analysis. Arch Intern Med. 2001;161:1613-1620. doi:10.1001/archinte.161.13.1613

17. Borenstein DG, Korn S. Efficacy of a low-dose regimen of cyclobenzaprine hydrochloride in acute muscle spasm: results of two placebo-controlled trials. Clin Ther. 2003;25:1056-1073. doi:10. 1016/S0149-2918(03)80067-X

18. Darwish M, Hellriegel ET. Steady-state pharmacokinetics of once-daily cyclobenzaprine extended release: a randomized, double-blind, 2-period crossover study in healthy volunteers. Clin Ther. 2011;33:746-753. doi:10.1016/j.clinthera.2011.05.045

19. Friedman BW, Dym AA, Davitt M, et al. Naproxen with cyclobenzaprine, oxycodone/ acetaminophen,or placebo for treating acute low back pain: a randomized clinical trial. JAMA. 2015;314:1572-1580. doi:10.1001/jama.2015.13043
20. Caron J, Kaye R, Wessel T, et al. An assessment of the centrally acting muscle relaxant tolperisone on driving ability and cognitive effects compared to placebo and cyclobenzaprine. J Clin Pharm Ther. 2020;45:774-782. doi:10.1111/jcpt.13165

21. Quasthoff S, Mockel C, Zieglgansberger W, et al. Tolperisone: a typical representative of a class of centrally acting muscle relaxants with less sedative side effects. CNS Neurosci Ther. 2008;14:107-119. doi:10.1111/j.1527-3458.2008.00044.x

22. Baratta RR. A double-blind study of cyclobenzaprine and placebo in the treatment of acute musculoskeletal conditions of the low back. Curr Ther Res. 1982;32:646-652.

\section{Publish your work in this journal}

The Journal of Pain Research is an international, peer reviewed, open access, online journal that welcomes laboratory and clinical findings in the fields of pain research and the prevention and management of pain. Original research, reviews, symposium reports, hypothesis formation and commentaries are all considered for publication. The manuscript

Submit your manuscript here: https://www.dovepress.com/journal-of-pain-research-journa management system is completely online and includes a very quick and fair peer-review system, which is all easy to use. Visit http:// www.dovepress.com/testimonials.php to read real quotes from published authors. 